\title{
Numerical simulation analysis of valve spool double- nozzle with abrasive flow
}

\author{
Junye $\mathrm{Li}^{1}$, Lili Wei ${ }^{2}$, Ningning $\mathrm{Su}^{3}$, Wenqing Meng ${ }^{4}$, Xinming Zhang \\ College of Mechanical and Electric Engineering, Changchun University of Science and Technology, \\ Changchun, 130022, China \\ ${ }^{5}$ Corresponding author \\ E-mail:11jy@cust.edu.cn, ${ }^{2916033207 @ q q . c o m, 3823969243 @ q q . c o m,{ }^{4} 1019448725 @ q q . c o m,}$ \\ 5fstving@126.com
}

Received 25 October 2017; accepted 2 November 2017

DOI https://doi.org/10.21595/vp.2017.19323

Check for updates

Abstract. In order to study the numerical simulation of abrasive flow polishing small hole parts, the servo valve spool double nozzle parts were used as the research object, and the solid-liquid two-phase abrasive flow were used for numerical simulation, getting the dynamic pressure, velocity cloud and turbulent kinetic energy of the abrasive flow are obtained at different inlet velocities. Through the comparative analysis, the effect of the process parameters on the effect of the abrasive flow polishing small hole parts was obtained, which can provide a theoretical basis for the continuous improvement of the ultra-precision machining technology to promote the abrasive flow, so that the fatigue strength of the workpiece is improved, the reliability of the workpiece is enhanced and its service life is prolonged.

Keywords: small hole parts, abrasive flow, numerical simulation.

\section{Introduction}

In the increasingly technological development today, the field of mechanical parts of the precision of the proposed higher requirements. Servo valve as a servo control system in a core servo control components, has been widely used in many areas of national life. Nozzle of the valve core is an important part in servo valve, the surface quality of nozzle will directly affect the servo valve performance, the traditional processing methods cannot ensure its quality and qualified rate. Abrasive flow processing technology provides effective solution for improving the quality of the surface of the servo valve nozzle, so the nozzle of abrasive flow machining technology has a certain theoretical significance and engineering practical significance [1-5].

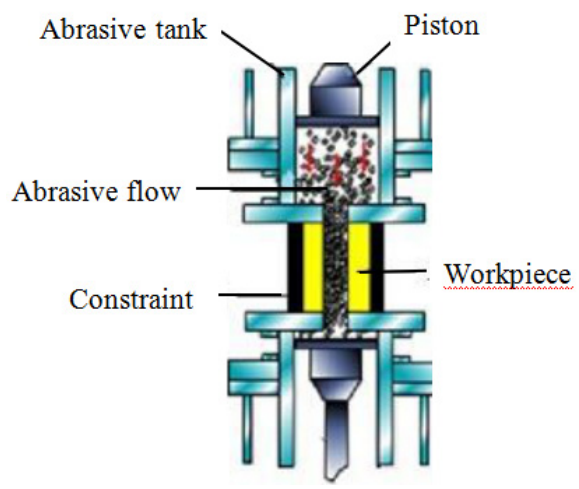

Fig. 1. Abrasive flow processing principle

The abrasive flow polishing process is a cost-effective new precision finishing process. The abrasive flow polishing technology has many advantages such as high polishing efficiency, automated production, good controllable performance, and high polishing surface quality. Compared with the traditional machining method, the abrasive flow polishing technology can use the abrasive media flow to the complex structure of the hole and cavity deep hole polishing 
processing, but also according to the application requirements of parts, selecting different abrasive media to polish the parts, so as to obtain different polishing effect to meet the requirements of parts, abrasive flow processing principle shown in Fig. 1 [6-10].

\section{Simulation analysis of solid - liquid two - phase abrasive flow polishing servo valve spool double nozzle}

In this paper, the double-nozzle of servo valve as the research object, because the double-nozzle in the rapid development of science and technology in general, so the double-nozzle processing accuracy requirements are high, so the need for ultra-precision machining. The double nozzle inlet diameter used is $1.5 \mathrm{~mm}$, the outlet diameter is $0.5 \mathrm{~mm}$, and the fluid part is shown in Fig. 2. In the initial setting, the large eddy simulation model and SIMPLE algorithm were used. $20 \%$ silicon carbide particles and hydraulic oil were used as the two - phase flow materials. The boundary conditions were selected for velocity inlet and free outlet. The inlet speed was $30 \mathrm{~m} / \mathrm{s}$, $35 \mathrm{~m} / \mathrm{s}, 40 \mathrm{~m} / \mathrm{s}$ and $45 \mathrm{~m} / \mathrm{s}$.

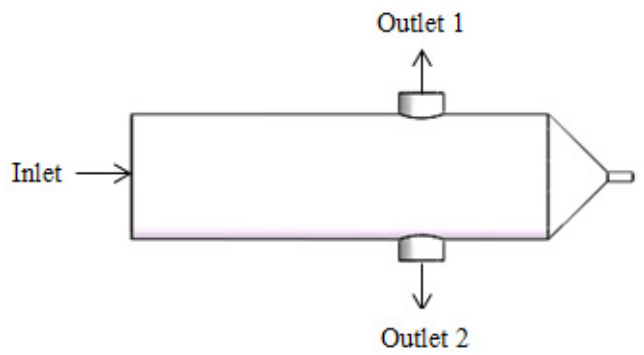

Fig. 2. Double nozzle fluid model

\subsection{Effect of different velocity on dynamic pressure}

First, the pressure field of the double nozzle is analyzed, and the dynamic pressure cloud image at different inlet speed is obtained, as shown in Fig. 3.

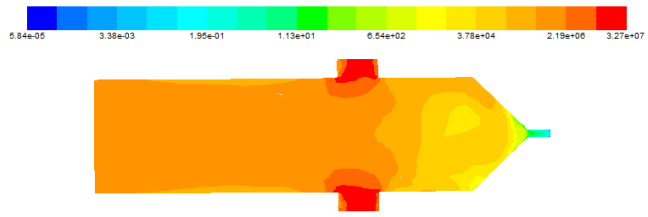

a) The inlet speed is $30 \mathrm{~m} / \mathrm{s}$

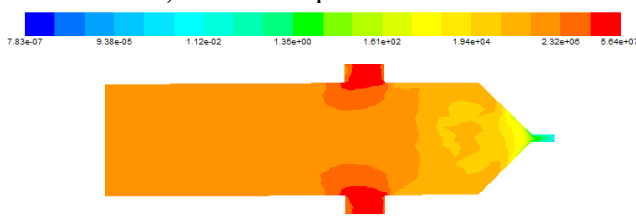

c) The inlet speed is $40 \mathrm{~m} / \mathrm{s}$

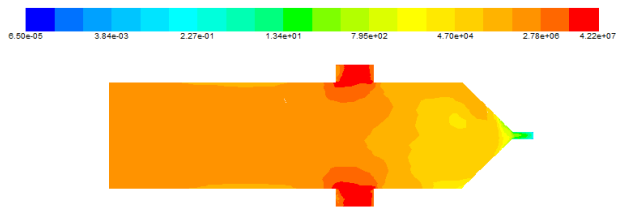

b) The inlet speed is $35 \mathrm{~m} / \mathrm{s}$

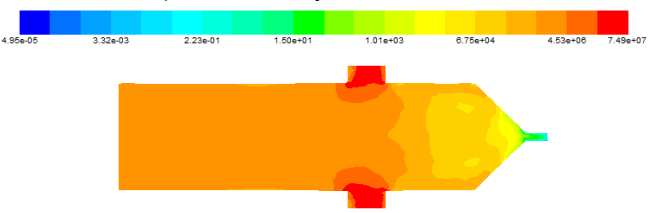

d) The inlet speed is $45 \mathrm{~m} / \mathrm{s}$

Fig. 3. Dynamic pressure at different inlet velocities

Fig. 3 shows that at different inlet velocities, the dynamic pressure simulation cloud is basically similar, the abrasive enters the injector from the inlet, and after the grinding of the injector workpiece, it flows out of the nozzle outlet. Dynamic pressure at the entrance of the smallest, after entering the double nozzle, the pressure did not change significantly at the exit due to cross-section suddenly smaller, resulting in significantly increased dynamic pressure, indicating the exit of the abrasive movement is more intense, better processing efficiency, because the speed is large, not 
all of the abrasive all out from the outlet, but a small part of the abrasive to continue to double the front of the nozzle for polishing, after touching the wall and then rebound to return from the exit. When the speed gradually increases, the dynamic pressure also increases, the processing effect is also improved.

\subsection{Effect of different entrance speed on polishing speed}

The comparison of the velocity of the abrasive flow of the servo valve spool double nozzle is shown in Fig. 4.

According to Fig. 4 we can see that with the increase in speed, the speed of the cloud has a slight change, the abrasive flow to a certain speed into the channel. Due to the role of abrasive media viscosity, will form a boundary layer in the near wall area, along the flow direction and gradually expand, the abrasive flow at the exit speed is relatively large. According to experience, we can see that the greater the speed of motion, the greater the chance of contact between the abrasive grains and the perforations in the abrasive grains, the better the processing effect. It can be seen from the velocity cloud diagram that with the increase of the inlet speed, the abrasive velocity also increases, which is beneficial to the finishing of the micro-pore structure.

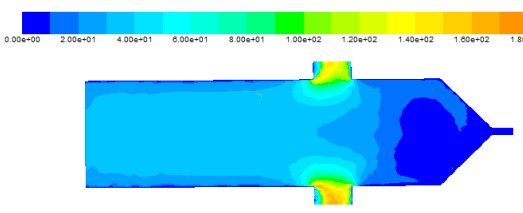

a) The inlet speed is $30 \mathrm{~m} / \mathrm{s}$

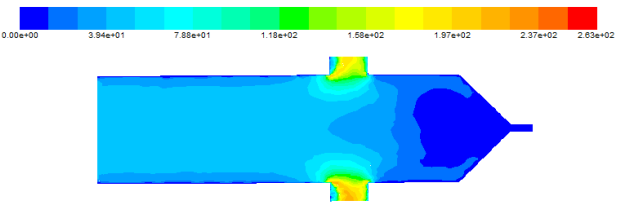

c) The inlet speed is $40 \mathrm{~m} / \mathrm{s}$

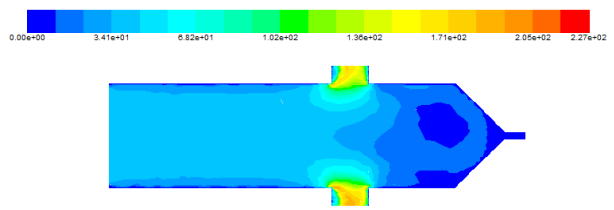

b) The inlet speed is $35 \mathrm{~m} / \mathrm{s}$

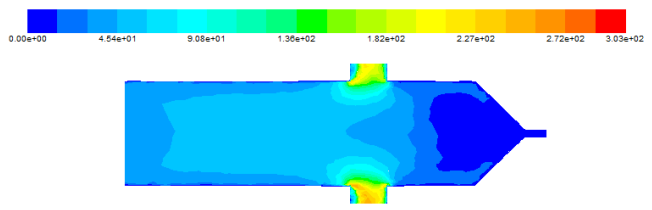

d) The inlet speed is $45 \mathrm{~m} / \mathrm{s}$

Fig. 4. Speed cloud of different inlet velocities

\section{3. fluence of different entrance velocity on turbulent kinetic energy}

The turbulence kinetic energy cloud at different inlet velocities is shown in Fig. 5.

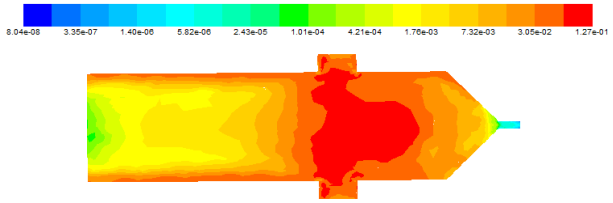

a) The inlet speed is $30 \mathrm{~m} / \mathrm{s}$

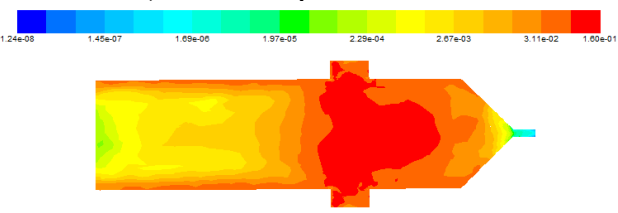

c) The inlet speed is $40 \mathrm{~m} / \mathrm{s}$

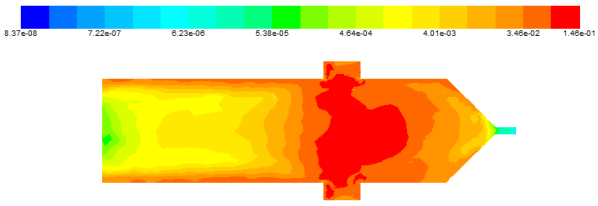

b) The inlet speed is $35 \mathrm{~m} / \mathrm{s}$

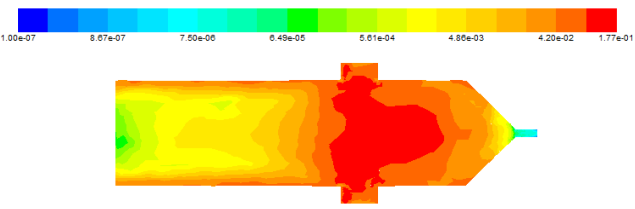

d) The inlet speed is $45 \mathrm{~m} / \mathrm{s}$

Fig. 5. Turbulence kinetic energy cloud at different inlet velocities

From the numerical simulation results of the turbulent kinetic energy, it is seen that the turbulent kinetic energy in the middle and the outlet of the spool core is much larger than that at 
the inlet, which indicates that the grinding media is more active at the nozzle outlet when the abrasive grains are polished, Which is beneficial to the deburring and chamfering of the nozzle outlet, so as to realize the finishing of the abrasive flow and improve the surface quality of the nozzle hole and the cross hole.

\section{Conclusions}

Through the analysis of the principle and motion of the abrasive flow, the processing characteristics of the abrasive grains at different speeds are discussed. The turbulent model and the solid-liquid two-phase large eddy model were used to simulate the flow pattern of the abrasive grains during the process of abrasive grain flow. The effect of abrasive flow on the processing of double nozzles at different speeds was analyzed. From the simulation results in this paper, we can draw the conclusions: The pressure, velocity and so on can be obtained by changing the inlet speed, and the abrasive flow of different processes is compared. With the increase of inlet speed, the dynamic pressure, velocity and turbulence kinetic energy increase. The increase of the inlet speed makes the effect of the abrasive flow on the processing effect of the double nozzle of the spool. Therefore, the proper increase of the inlet speed can improve the surface roughness of the workpiece, so that the workpiece can achieve the desired processing effect, which provides a theoretical basis for the optimization of the parameters of the grinding fluid flow. The fatigue strength of the machined parts is improved, the reliability of the parts is enhanced, and the service life is prolonged.

\section{Acknowledgements}

The authors would like to thank the National Natural Science Foundation of China No. NSFC 51206011, Jilin Province Science and Technology Development Program of Jilin Province No. 20160101270JC and No. 20170204064GX, Project of Education Department of Jilin Province No. 2016386.

\section{References}

[1] Li Jun Ye, Liu Wei Na, Yang Li Feng, Etal Design and numerical simulation of grain flow processing equipment for common mesh tubing. Mechanical Design and Manufacture, Vol. 10, 2010, p. 54-56.

[2] Li Jun Ye, Liu Wei Na, Yang Li Feng, et al. Numerical simulation of the processing characteristics of the micro-hole of the injector. Coal Mine Machinery, Vol. 31, Issue 10, 2010, p. 56-58.

[3] Timing Ming, Zhong Jiaqi, Tan Dapeng, et al. Particle group distribution and its dynamic characteristics of different particle concentration in structured flow. Journal of Agricultural Engineering, Vol. 28, Issue 4, 2012, p. 45-53.

[4] Timing Ming, Wang Jiaqi, Tan Dapeng, et al. Effects of particle collision and particle volume fraction on grinding effect in soft abrasive grains. Journal of Applied Basic and Engineering Sciences, Vol. 21, Issue 5, 2013, p. 927-937.

[5] Salikov V., Antonyuk S., Heinrich S., et al. Using DPM on the way to tailored prismatic spouted beds. Chemie Ingenieur Technik, Vol. 84, Issue 3, 2012, p. 388-394.

[6] Tarpagkou R., Pantokratoras A. CFD methodology for sedimentation tanks: The effect of secondary phase on fluid phase using DPM coupled calculations. Applied Mathematical Modeling, Vol. 37, Issue 5, 2012, p. 3478-3494.

[7] Gorana V. K., Jain V. K., Lal G. K. Forces prediction during material deformation in abrasive flow machining. Wear, Vol. 260, Issue 1, 2005, p. 128-139.

[8] Walia R. S., Shan H. S., Kumar P. Enhancing AFM process productivity through improved fixturing. The International Journal of Advanced Manufacturing Technology, Vol. 44, Issue 7, 2009, p. 700-709.

[9] Tan Yuan Qiang, Li Yi Study on model and pressure characteristics of solid-liquid two-phase flow in abrasive flow processing. China Mechanical Engineering, Vol. 19, Issue 4, 2008, p. 439-497.

[10] Gao Hang, Wu Mingyu, Fu Youzhi et al. Development of theory and technology of liquid abrasive finishing. Journal of Mechanical Engineering, Vol. 51, Issue 7, 2015, p. 174-187. 